\title{
Mass Stabilization as reinforcement of organic soils
}

\author{
Grzegorz Nowak ${ }^{1, *}$ and Piotr Kanty ${ }^{2}$ \\ ${ }^{1}$ Wroclaw University of Science and Technology, Wyb. Wyspiańskiego 27, 50-370 Wrocław, Poland \\ ${ }^{2}$ MENARD Polska Sp. z o.o. ul. Powązkowska 44c, 01-797 Warsaw, Poland
}

\begin{abstract}
The decreasing number of places suitable for constructing buildings forces people to creatively develop newer methods of soil reinforcement. One of these methods is the deep soil mixing. This technology has been firstly developed and applied in Japan in the 1970s. Initially, it was used to create DSM (Deep Soil Mixing) columns. In the subsequent years, it was also developed in Scandinavia. Over time, the deep mixing technology was modified and developed, and in addition to the wet method, also the dry method was started to be used, while in addition to the cement binder, also lime binders and fly ashes were used. Technologies consisting of the deep mixing of cement with soil are very popular due to the wide range of applications and relatively low implementation costs. The method of Mass Stabilization (MS) is a soil reinforcement method that is analogical to DSM and it consists of mixing large volumes of soil with cement. This article describes the method of dry Mass Stabilization of organic soils. It cites the analyzed laboratory tests of soil-cement material manufactured in MS technology. The tests included the creation of 140 material samples, and subsequently the performance of compression strength test on them, along with the registration of stress path. The main aspect of these tests consisted of increase in the primary deformation modulus over time, depending on the amount of applied cement. Also, an example of the project to strengthen the layer of aggregate mud under the floor in the hall is demonstrated. The reinforcement was implemented in the MS technology.
\end{abstract}

\section{Introduction - scope of the work}

The increasing human population results in the growing density of buildings, particularly in the cities. This is associated with the construction of buildings on low-bearing or even organic soils. This is possible due to the use of many types of soil reinforcements, while the simplest of them is the replacement of soil, consisting of the removal of non-bearing soil and replacing it with a load-bearing soil, with freely selected parameters, which are determined by the designer. If the thickness of the weak layer is high and the replacement of soil is unprofitable, then it is necessary to use alternative reinforcements, such as piles or various methods of soil improvement or soil stabilization $[1,2]$.

\footnotetext{
* Corresponding author: 225095@student.pwr.edu.pl
} 


\subsection{Basics of Deep Soil Mixing (DSM) technology}

Reinforcement through the use of piles or columns is associated with the transfer of forces from the structure to the bearing layer, while bypassing the non-bearing layers. Therefore, the piles are good solution, when there are numerous interbeddings of weak soils. It is also possible to strengthen the soil by static or dynamic compaction. An alternative to these methods is the deep mixing of the soil with various types of binders and this type of soil reinforcement is becoming increasingly popular in Poland.

Development of the deep soil mixing methods is described in the work [3], which includes the presentation of the current state and progress noted mainly in the European context, while references to the application of this technology in Poland can be found in the works $[4,5]$. Deep soil mixing is mainly used in reference to the DSM (Deep Soil Mixing) wet technology, which consists of creation of the soil columns, in which the cement slurry or lime slurry is the binder. More information about technological and strength aspects can be found in the doctor's thesis of Leśniewska [6]. In the deep mixing technology, the main component of created material is the soil. This results in the uncertainty, whether the designed product will have the assumed strength parameters. The possible methods for controlling the quality of the soil-cement material are presented in [7]. General remarks regarding geotechnical projects and supervision over them are contained in the work [8]. This paper presents the method of dry mass stabilization in organic soils, such as peats. This method is also described in the book "Peat" [9], as well as in the paper [10], where the use of a mixture of cement with blast furnace slag was considered as a binder

\subsection{Description of Mass Stabilization (MS) technology}

Mass Stabilisation originates from Scandinavia, where it is very popular due to specific soil conditions. The stabilisation process consists of deep mixing of the soil along with the binder. Two following types of this method can be distinguished:

- Dry Mass Stabilisation,

- Wet Mass Stabilisation.

They differ significantly not only in terms of the state of binder introduced into the soil, dry stabilisation - dry cement, lime or ashes, wet stabilisation - cement slurry, cement-lime slurry, etc., but also in terms of the achieved product strength.

During performance of stabilisation, the first stage is the introduction of a rotating head, which is supposed to destroy the primary structure of the soil, and then the binder is introduced in a dry form or in a slurry form (depending on the method), which will be the binding factor. After thorough mixing of the binder and soil, the mixing machine moves to the next place. After performance of stabilisation, it is necessary to check the parameters of created soil-cement material, such as: compressive strength and deformability. Depending on the occurring soil conditions, the suitable types should be used. Dry stabilisation should be applied in the case of organic and cohesive soils, while wet stabilisation should be used in the case of cohesive and powdery soils.

The risk of using the wet method for reinforcement of organic soils is presented in the works [11] and [12]. During the use of dry method, it is possible to achieve drying of the soil and this effect results from the hydrophilicity of the binders, which need water in order to start the binding process. The soil drying agent is also the heat generated by hydration during the process of binding. Water is an extremely important factor in this technology, particularly in the case of dry method, therefore one of the conditions for using this method is natural moisture content of the soil at the level exceeding $60 \%$. Such high, as well as higher natural moisture content occurs in organic soils, therefore MS is recommended for the reinforcement of organic soils. 


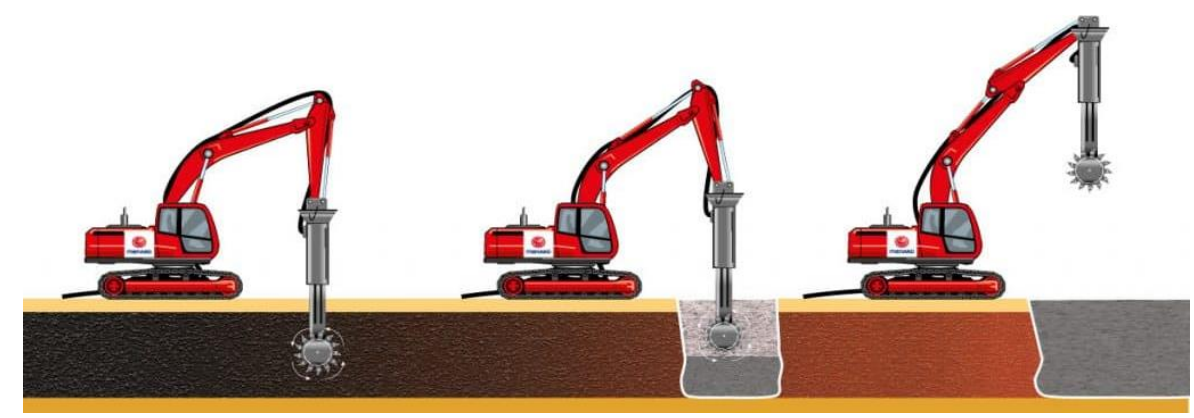

Fig. 1. Process of mass stabilization https://www.menard.pl/

\section{Tests of soil-cement material samples}

Over hundred and forty samples of soil-cement material samples in the dry mixing technology were created as part of the order of Menard Polska sp. z o.o. The soil, which mostly consisted of peat with admixtures of clays, was delivered from the construction site, where the mass stabilisation was supposed to be implemented. These tests have also been presented in the works $[13,14]$, where the focus was on determining the optimal time for quality control of the material, as well as demonstrating the changes in strength parameters depending on the time and amount of used cement. Another work focusing on the aspect of dependence of the strength increase along with the increase in the amount of cement in the material is [15]. In the discussed case, the hydraulic cement was used as a binder. Besides the cement, it is also possible to use mixtures of cement with fly ashes, which is described in more detail in the work [16], as well as in the work [12]. All tests were carried out in a similar way to the one proposed in [12], with the necessary modifications resulting from different technology (dry).

\subsection{Process of sample creation}

Samples of the soil-cement material were created from the soil collected within the construction site and cement (CEM IIIA $32.5 \mathrm{~N} / \mathrm{LH} / \mathrm{HSR} / \mathrm{NA}$ that exhibits the strength circa $22.0 \mathrm{MPa}$ only after 7 days). Cement amount varied from $129 \mathrm{~kg} / \mathrm{m}^{3}$ to $226 \mathrm{~kg} / \mathrm{m}^{3}$ in the achieved composite. The soil was pre-homogenised before mixing, then two soil samples were collected, in order to determine their organic content and natural moisture content in the laboratory. Then, a measured amount of cement was added to the previously weighed soil, which was mixed with the soil using a mechanical stirrer. After thorough mixing, a cubic moulds with the dimensions of $15 \times 15 \times 15 \mathrm{~cm}$ were filled with the mixtures, and the samples remained in these moulds for seven days until demoulding. 17 series of samples were created, each series with different cement content, natural moisture content and organic content and each series contained a minimum of 7 samples. After demoulding, it was possible to notice a specific structure of the soil - extensive porosity was visible, which is caused by sticking of cement to larger clumps of soil - it can be seen in Figure 4.

\subsection{Tests of soil samples}

The soil samples were tested in order to determine the content of organic parts and the natural moisture content of the soil used to produce the soil-cement material sample. Determination of natural moisture content was implemented by placing part of the soil in 
evaporators, which were previously weighed, and then the mass of evaporator with the soil in a wet state was determined.

The evaporators were placed in the evaporating dish, in which, under the influence of elevated temperature, the water evaporated from the soil, which allowed to determine the mass of the soil skeleton and subsequently the natural moisture content. Determination of the content of organic parts was carried out by burning out the previously dried samples, and then the determination of the mass of samples after burning out, and comparing the mass of samples after burning out to the mass of samples before burning out. The natural moisture content of the samples ranged from $37.4 \%$ to $56.2 \%$, while the content of organic parts ranged from $5.75 \%$ to $7.95 \%$.

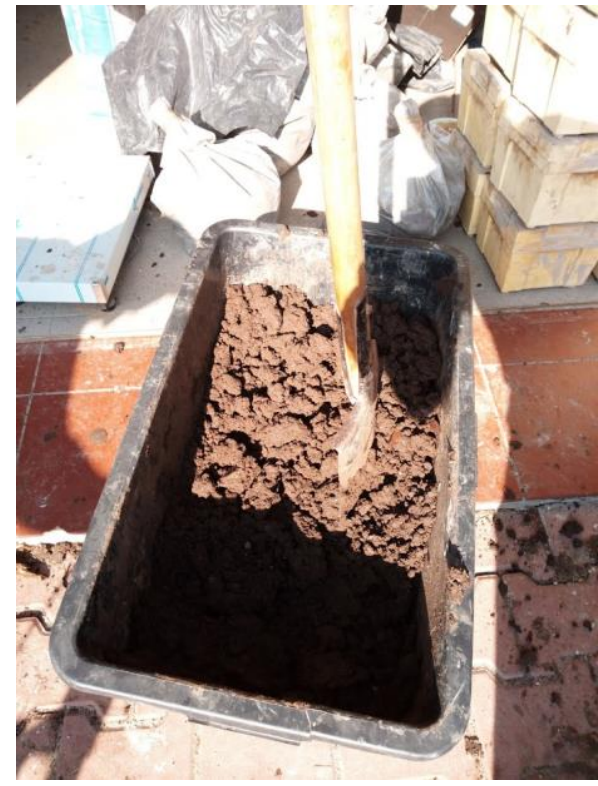

Fig. 2. Initial homogenization of the soil

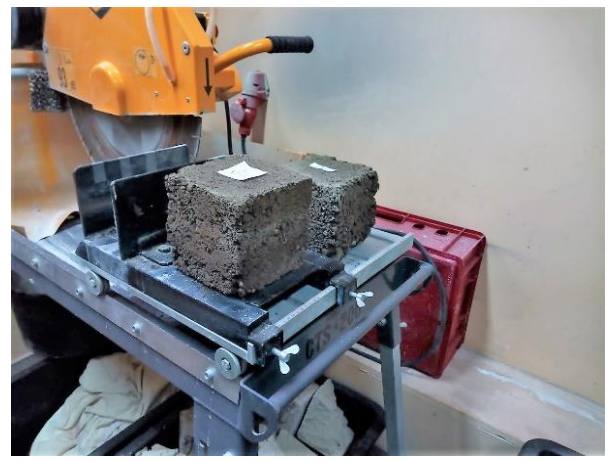

Fig. 4. Samples before destruction

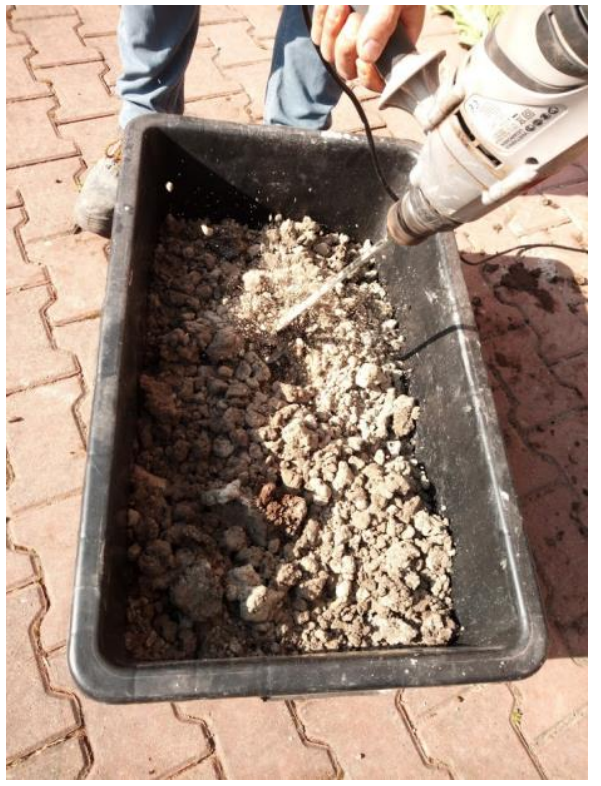

Fig. 3. Mixing of the soil with cement binder

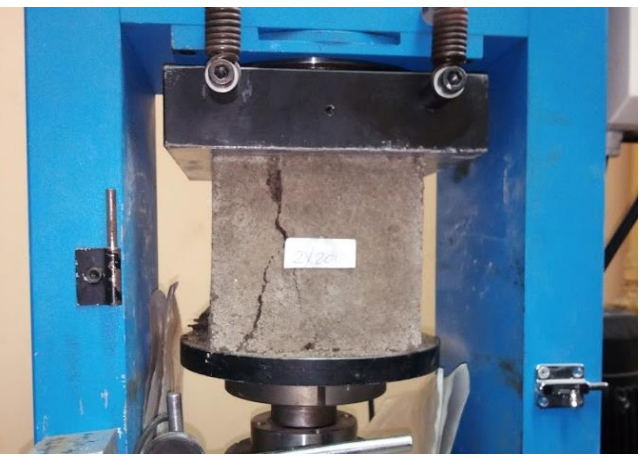

Fig. 5. Samples after compression test 


\subsection{Strength tests}

The strength tests of each series were conducted after seven, fourteen, twenty-eight, fiftysix and eighty-four days. A stress path, deformation modulus and compressive strength were determined for each sample. Subsequently, the analysis of test results was conducted.

\section{Analysis of strength test results}

The method of analyzing data obtained from the tests was based on the method presented by Kanty [12] and data presented in the studies [13-16] were analyzed in a similar manner. The methodology of analysis is analogical to the concrete tests, while the difference consists of the fact that in the graphs of deformation stresses, the first part of the graph is not taken into account, because it is unreliable due to the press adaption to the uneven surface of the sample. A different analysis was conducted by Piasecki, who in his work [17] examined the microstructure of soil-cement, which may be useful in analyzing the strength results - it allows to find the composite weaknesses.

\subsection{Methodology of analysis}

The tests were implemented in a static universal testing machine with the registration of deformation path. The forces acting on the sample over time and displacements of the compression head were registered. With the use of formulas (1) and (2), results were obtained in the form of stresses expressed in megapascals (MPa) and deformations expressed in percents. Subsequently, the graphs were generated from the obtained results. The analysis of results in the article [18] was conducted in a similar manner.

$$
\sigma=\frac{F}{S}[\mathrm{MPa}]
$$

where: $\sigma$-stresses, $F$ - forces, $S$-sample section area.

$$
\varepsilon=\frac{\Delta h}{h}[\%]
$$

whwre: $\varepsilon$-deformations, $\Delta h$ - difference in the sample height, $h$-sample height.

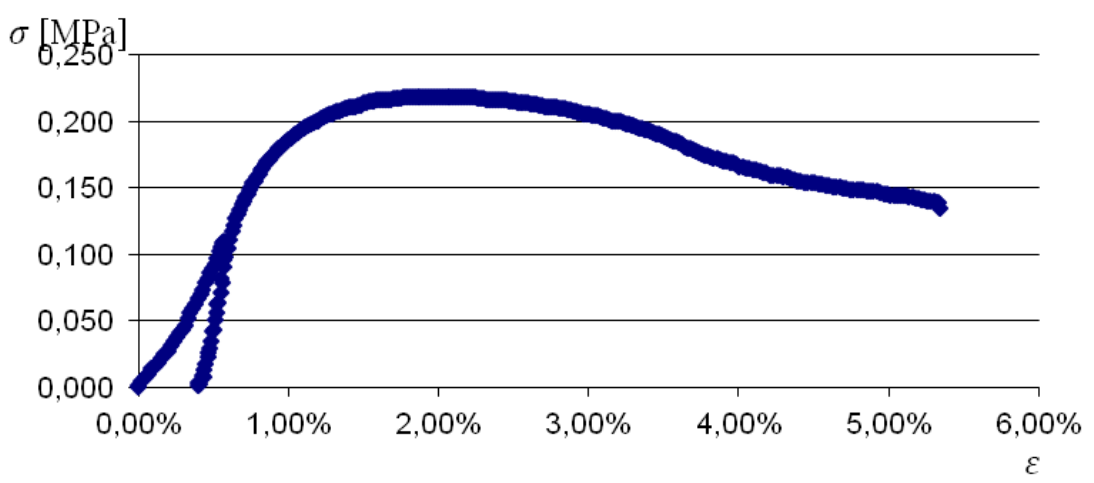

Fig. 6. Stresses to deformations dependence

The maximum stress value that occurred during the test was read from the above graph. It is the compressive strength of the soil-cement material sample $R_{c}=0.22 \mathrm{MPa}$. The values of deformation moduli $\mathrm{E}_{50}$ and $\mathrm{E}_{2}$ - were determined by extracting the initial straight sections 
from Figure 6, for which the Hooke's law is fulfilled (considering the initial bedding error in course of the compression test). Subsequently, the formulas of straight lines were determined from the graphs, near which the results are located. Slopes of linear functions correspond to the deformation moduli.

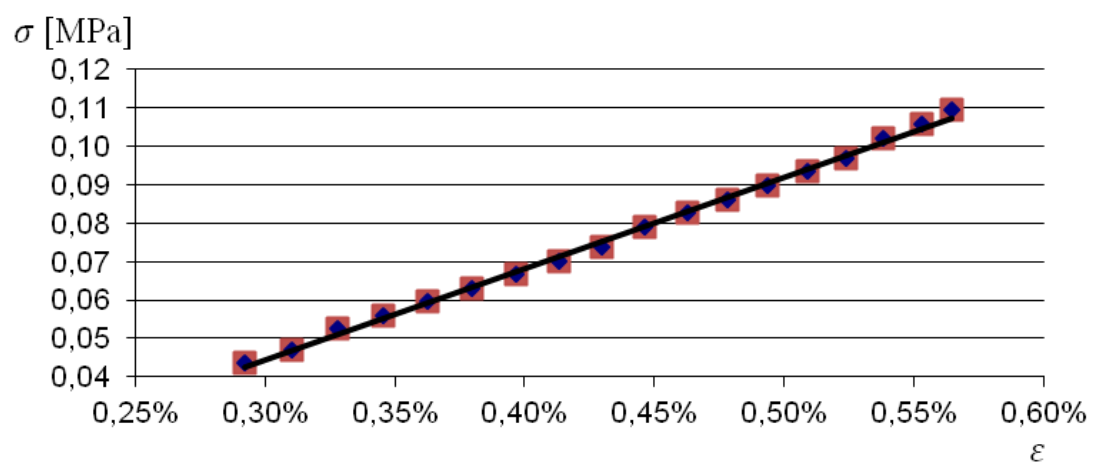

Fig. 7. The part of Figure 6 corresponding to primary deformations

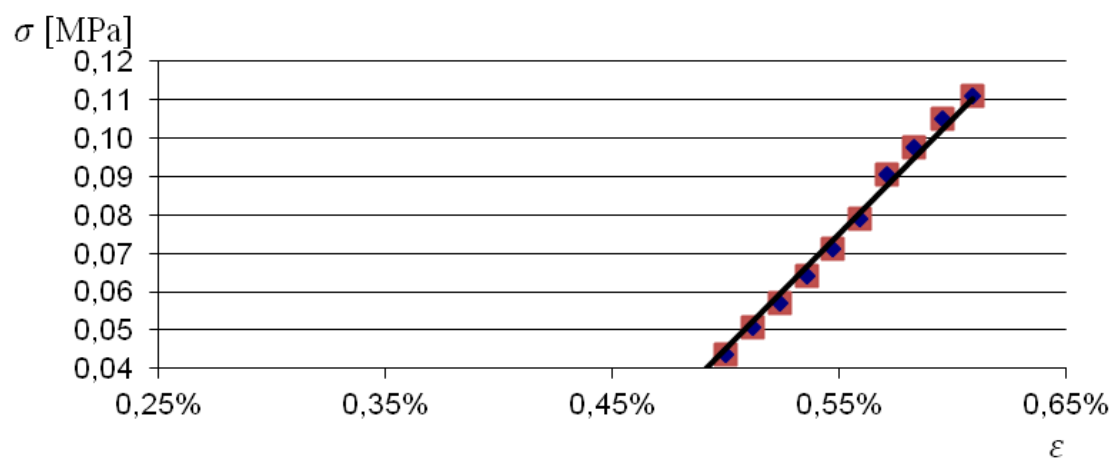

Fig. 8. The part of Figure 6 corresponding to unloading-reloading- deformations

It can be concluded from the analysis of Figures 7 and 8 that the $\mathrm{E}_{50}$ primary deformation modulus amounts to $23.75 \mathrm{MPa}$, while the $\mathrm{E}_{2}$ secondary deformation modulus is equal to $59.93 \mathrm{MPa}$. Obtaining the secondary deformation modulus required stopping of the universal testing machine at the moment when the compressive force reached the limit of proportionality in regard to the deformations. Subsequently, the compressive force was reduced to zero and the compression process was started again.

This way, the analysis of all samples was conducted, which resulted in a large database of results, thanks to which it was possible to check how the soil-cement material behaves over time and depending on the amount of cement.

\section{Presentation of deformation moduli over time}

\subsection{Comparison of deformability moduli for various cement contents}

Depending on the amount of cement, different values of the primary and secondary moduli could be seen in the results, while the increase in moduli can be observed along with the increase in the cement content. This is not a linear increase and this results from the 
impression of individual samples. Due to the specific process of compaction of the samples, consisting of compacting the slurry of soil-cement material, it was not possible to obtain samples comparable in terms of mass. Even small differences in the mass and, which is associated with this, in the material density caused differences in the results - more compacted samples obtained larger moduli from than less compacted samples.

The results for four selected series with cement contents from $129 \mathrm{~kg} / \mathrm{m}^{3}$ to $226 \mathrm{~kg} / \mathrm{m}^{3}$ are demonstrated in the graph below.

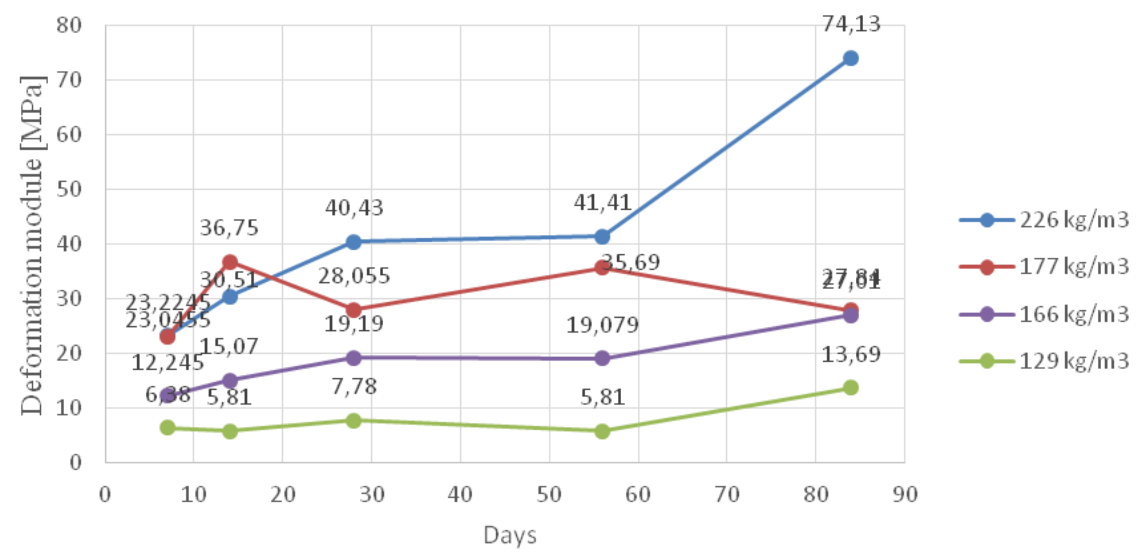

Fig. 9. Dependence of primary deformability modulus from days after sample moulding

The secondary deformation modulus, which was determined 28 days after moulding for the example series, is also of great importance during the design due to the settlement. In most cases, this modulus is more than twice as large as the primary modulus, which is another fact demonstrating that the organic soil-cement material is strongly influenced by the appropriate compaction. It can also be observed that the difference between the moduli becomes blurred along with the increase in the cement amount.

Table 1. Results of primary deformability $\left(\mathrm{E}_{50}\right)$ vs. secondary deformability $\left(\mathrm{E}_{2}\right)$

\begin{tabular}{|c|c|c|c|}
\hline Cement content & $\begin{array}{c}\text { Mean } \mathbf{E}_{\mathbf{5 0}} \\
\text { after 28 days }\end{array}$ & $\mathbf{E}_{\mathbf{2}}$ after 28 days & $\mathbf{E}_{\mathbf{2}} / \mathbf{E}_{\mathbf{5 0}}$ \\
\hline $\mathbf{k g} / \mathbf{m}^{\mathbf{3}}$ & $\mathbf{M P a}$ & $\mathbf{M P a}$ & - \\
\hline 129 & 7.78 & 25.49 & 3.28 \\
\hline 166 & 19.19 & 59.93 & 3.12 \\
\hline 177 & 28.06 & 65.20 & 2.32 \\
\hline 226 & 40.43 & 75.62 & 1.87 \\
\hline
\end{tabular}

The above-mentioned data was used to design the reinforcement under the floor in the warehouse hall. The fragments of this project were presented in the further part of the work.

\section{Case study}

In this case, the problem consisted of reinforcement of the three-metre layer of aggregated mud located under the non-construction embankment layer and these soils were located in the area designated for the high storage warehouse hall. The load acting on the soil 
amounted to $50 \mathrm{kN} / \mathrm{m}^{2}$, which constituted too heavy load to leave the soil without reinforcement, due to settlement exceeding the acceptable limit of $50 \mathrm{~mm}$. Due to the occurring confined water table, it was decided to implement reinforcement in the dry mass stabilisation technology, which will allow to partially dry the soil, while the water contained in the soil will help in the bonding process.

\subsection{Reinforcement implementation technology and numerical calculations}

After removing the surface layer of humus, it was necessary to make an excavation to the level of the stabilised water table. Subsequently, the mass stabilisation was initiated, which covered the remaining layer of non-construction embankments and the entire layer of aggregate mud. Stabilisation should be performed in a manner that ensures thorough destruction of the primary structure of reinforced layer, in order to allow the stabilisation of water closed under this layer. The water that will flow out will be bound with the cement and this will favourably affect the process of substrate stabilisation. Subsequently, the excavation was filled with the floor bedding, which caused a static compaction of the soilcement material layer.

The settlement calculations were carried out in the GEO5 software, which uses the finite element method. The elastic-plastic (Mohr-Coulomb) material model was assumed. Four models of reinforcement were made and one model without reinforcement. In accordance with the predictions, the settlements decreased for the models with a higher cement content per cubic metre, however for the model with the lowest amount of cement, the settlements were satisfactory enough that it could be successfully adopted for further design. The results obtained during the selection of the appropriate technology are summarized below.

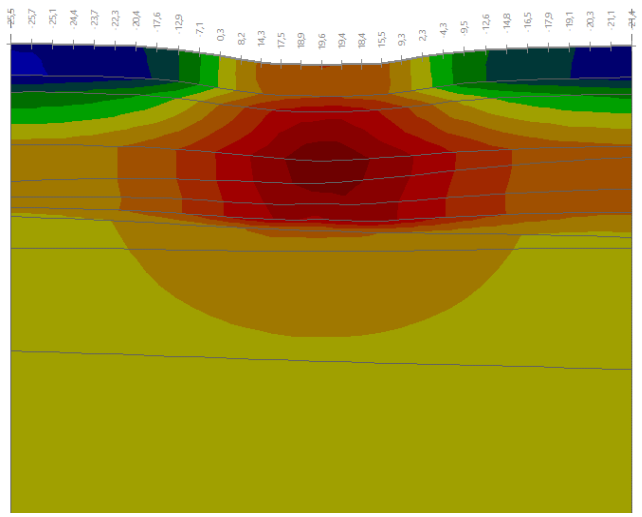

Fig. 10. Model for $129 \mathrm{~kg} / \mathrm{m}^{3}$ of cement, settlements $19.6 \mathrm{~mm}$

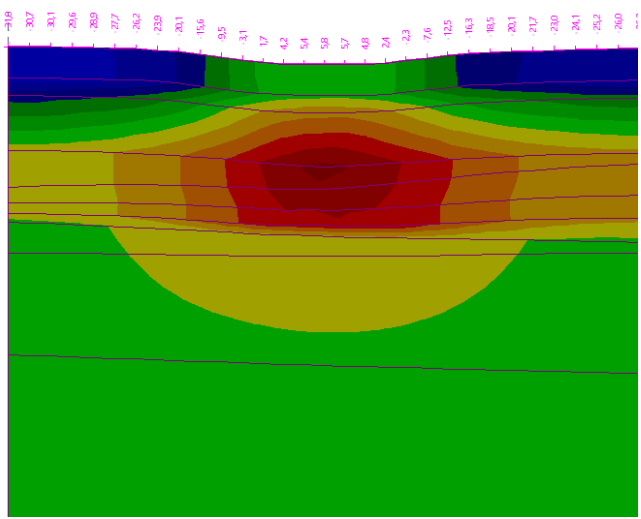

Fig. 11. Model for $166 \mathrm{~kg} / \mathrm{m}^{3}$ of cement, settlements $5.8 \mathrm{~mm}$ 


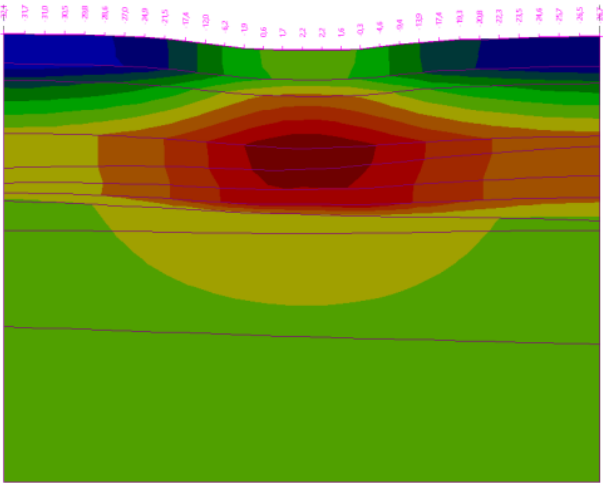

Fig. 12. Model for $177 \mathrm{~kg} / \mathrm{m}^{3}$ of cement, settlements $2.2 \mathrm{~mm}$

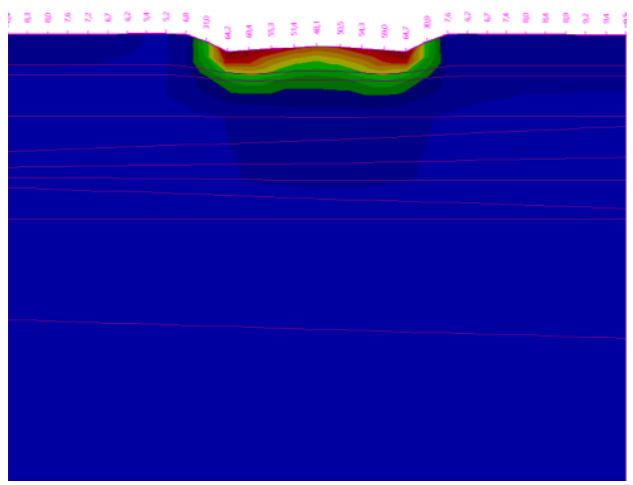

Fig. 14. Model without reinforcement, settlements $64.7 \mathrm{~mm}$ at $18 \%$ load

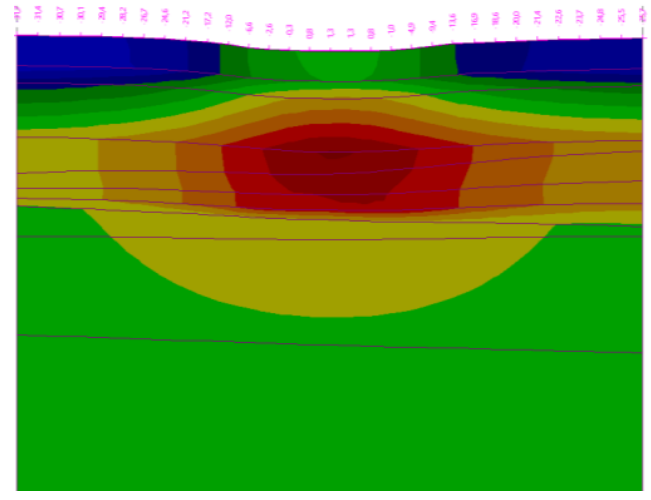

Fig. 13. Model for $226 \mathrm{~kg} / \mathrm{m}^{3}$ of cement, settlements $1.3 \mathrm{~mm}$

While analysing the results, it can be seen that even with the use of technology with the smallest amount of cement, the satisfactory results can be obtained, above all for economic reasons. It can be also observed that without reinforcement, the soil settlement will be greater than the acceptable $50 \mathrm{~mm}$ already at $18 \%$ of the load . Further steps for higher load have not been carried out, because the soil model used in the program has been destroyed. However, compressive strength of soilcement composite based on organic soil is not impressive, its stiffness can be seriously increased by means of dry mixing.

Table 2. Juxtaposition of settlement results

\begin{tabular}{|c|c|c|c|c|}
\hline \multirow{2}{*}{ Model } & Cement content & $\begin{array}{c}\text { Soil } \\
\text { stress relief }\end{array}$ & $\begin{array}{c}\text { Soil } \\
\text { settlement }\end{array}$ & $\begin{array}{c}\text { Settlement- } \\
\text { stress relief } \\
\text { difference }\end{array}$ \\
\cline { 2 - 5 } & $\mathrm{kg} / \mathrm{m}^{3}$ & $\mathrm{~mm}$ & $\mathrm{~mm}$ & $\mathrm{~mm}$ \\
\hline 1 & 129 & -25.5 & 19.6 & 45.1 \\
\hline 2 & 166 & -32.8 & 5.8 & 38.6 \\
\hline 3 & 177 & -33.9 & 2.2 & 36.1 \\
\hline 4 & 226 & -33.6 & 1.3 & 34.9 \\
\hline Not improved & 0 & 0.0 & 64.7 & 64.7 \\
\hline
\end{tabular}

\section{Conclusions}

While analysing the results of research, a large dependence of strength parameters on the amount of cement can be observed and the authors of the article [19] reached similar conclusions. It can be also seen how small amount of cement can affect the load-bearing capacity of the substrate. This means that even with the small financial expenses, it is 
possible to obtain satisfactory strength results of the substrate. The performed research will allow in the future to more accurately analyse the implementation technology of mass stabilisation in the economic aspect [20]. It is also worth to notice a high variability of results, which is probably caused by varying degree of compaction for individual samples. Thus, it is necessary to remember during the design process about the creation of the consolidation possibility for soil-cement material even before the commencement of binding.

The authors would like to address the gratitude to laboratory stuff at the Faculty of Civil Engineering at Wroclaw University of Science and Technology for their kind assistance. Results of the current study formed the basis for Eng. diploma thesis of the author - Grzegorz Nowak. The current study is a part of research grant no. 45WB/0001/17 - "Industrialized construction process (construction 4.0)"

\section{References}

1. J. Forsman H. Jyrävä P. Lahtinen T. Niemelin I. Hyvönen. Mass stabilization manual. http://projektit.ramboll.fi/massastabilointi/materials/mass_stabilization_manual_2015.pdf

2. Design Guide: Soft Soil Stabilisation: EuroSoilStab: Development of Design and Construction Methods to Stabilise Soft Organic Soils, IHS BRE Press, ISBN1860815995, (2010)

3. M. Topolnicki, Soil mixing - challenges of applications ranging from ground improvement to structural elements, XIII. Danube-European Conf. on Geotechnical Engineering, Ljubljana, 29-31.05.2006, 1-6 (2006)

4. M. Topolnicki, Design and execution practice of wet Soil Mixing in Poland, Int. Symp. on Deep Mixing \& Admixture Stabilization, Okinawa, 19-21 May, 195-202 (2009)

5. M. Topolnicki, General overview and advances in Deep Soil Mixing", XXIV Geotechnical Conference of Torino Design, Construction and Controls of Soil Improvement Systems, Torino, 25-26.02.2016, 1-30 (2016)

6. A. Leśniewska, Strength and technological issues of soil improvement by means of Deep Soil Mixing Wet technology. Doctor's Thesis, Gdańsk University of Science and Technology, (2007) (in Polish)

7. J.L. Chaumeny, P. Kanty, T. Reitmeier, Remarks on wet deep soil mixing quality control, XVI Danube - European Conf. on Geotechnical Engineering, 07-09 June 2018, Skopje, R. Macedonia, 039 (2018)

8. D. Sobala, J. Rybak, Role to be played by independent geotechnical supervision in the foundation for bridge construction, IOP Conf. Ser.: Mater. Sci. Eng., 245, 022073 (2017)

9. L. Korkiala-Tanttu, J. Forsman, P. Piispanen, Mass Stabilization as a Ground Improvement Method for Soft Peaty Soil, "Peat" InTechOpen ISBN: 978-1-78923-7474 (2018)

10. M.J. Timoney, B.A. McCabe and A.L. Bell, Experiences of dry soil mixing in highly organic soils. Proc. Inst. Civ. Eng. - Ground Improvement, 165, 3-14 (2012)

11. P. Kanty, J. Rybak and D. Stefaniuk, Risk related to deep soil mixing in organic soils, Integraciâ, partnerstvo i innovacii v stroitel'noj nauke i obrazovanii, 16-17 noâbrâ 2016, Moskva : NIU MGSU, 894-899 (2016)

12. P. Kanty, J. Rybak and D. Stefaniuk, Some remarks on practical aspects of laboratory testing of deep soil mixing composites achieved in organic soils, IOP Conf. Ser.: Mater. Sci. Eng., 245, 022018 (2017)

13. M. Kiecana, P. Kanty, K. Łużyńska, Optimal control time evaluation for "dry DSM" soil-cement composites, MATEC Web Conf., 251, 01023 (2018)

14. K. Jendrysik, M. Kiecana, H. Szabowicz, Preliminary results of dry Deep Soil Mixing soil-cement composite testing, MATEC Web Conf., 251, 01025 (2018) 
15. I. Karpisz, J. Pyda, L. Cichy, D. Sobala, Study of the effect of cement amount on the soil-cement sample strength, IOP Conf. Ser.: Mater. Sci. Eng., 365, 042061 (2018)

16. I. Karpisz, K. Jaworski, Study of compressive strength evolution in soil cement samples with fly-ash admixtures. IOP Conf. Ser.: Mater. Sci. Eng., 365, 032049 (2018)

17. D. Piasecki, D. Stefaniuk, Micro-scale laboratory investigation of cement-soils composite, Stroitel'stvo-formirovanie sredy žiznedeâtel'nosti, Moskva, 27-29 aprilâ 2016. Moskva : NIU MGSU, 1061-65 (2016)

18. A.A. Egorova, J. Rybak, D. Stefaniuk, P. Zajączkowski, Basic aspects of deep soil mixing technology control. IOP Conf. Ser.: Mat. Science and Eng., 245, 022019 (2017)

19. K. Brasse, T, Tracz, T. Zdeb, P. Rychlewski, Influence of Soil-Cement Composition on its Selected Properties. MATEC Web Conf., 163, 06006 (2018)

20. P. Rychlewski, Wzmacnianie gruntów pod nasypami infrastruktury komunikacyjnej, GDMT, 52 (3/2018), 36-43 (2018) [in Polish] 